\title{
Regulation of fuel metabolism during exercise in hypopituitarism with growth hormone- deficiency (GHD)
}

Thomas Zueger ${ }^{*}$, MD; Hannah Loher ${ }^{1 *}, \mathrm{MSc}$; Andrea Egger ${ }^{2}, \mathrm{MD}$; Chris Boesch ${ }^{3}, \mathrm{MD} \mathrm{PhD}$; Emanuel Christ ${ }^{1}, \mathrm{MD} \mathrm{PhD}$

1. Division of Endocrinology, Diabetes and Clinical Nutrition, Inselspital, Bern University Hospital, and University of Bern, Switzerland

2. Department of Internal Medicine, University Hospital of Basel, CH-4056 Basel, Switzerland

3. Department of Clinical Research \& Institute of Interventional, Diagnostic and Pediatric Radiology, University of Bern, Bern, Switzerland

*T. Zueger and H. Loher have equally contributed to this manuscript

\section{Running title:}

Fuel metabolism in GHD patients during exercise

\section{Correspondence and reprint requests to:}

Emanuel Christ, MD PhD

Division of Endocrinology, Diabetes and Clinical Nutrition

Inselspital, Bern University Hospital, and University of Bern

CH-3010 Bern

Switzerland

Email: emanuel.christ@insel.ch

Phone: +41316324070

Fax: +41316328414

\section{Word Count:}

Abstract 250 words, main text 2549 words

\section{Funding/Grants:}

The work was funded by grants from the Swiss National Science Foundation to Emanuel R. Christ (No. \#32000B0-100146).

Disclosure Statement: The authors have nothing to disclose.

Conflict of interest: None

Clinical Trial Registration Number: Clinical.Trials.gov: NCT00491582 


\begin{abstract}
$\underline{\text { ABSTRACT }}$

\section{Objective}

Growth hormone $(\mathrm{GH})$ has a strong lipolytic action and its secretion is increased during exercise. Data on fuel metabolism and its hormonal regulation during prolonged exercise in patients with growth hormone deficiency (GHD) is scarce. This study aimed at evaluating the hormonal and metabolic response during aerobic exercise in GHD patients.
\end{abstract}

\title{
Design
}

Ten patients with confirmed GHD and 10 healthy control individuals (CI) matched for age, sex, BMI, and waist performed a spiroergometric test to determine exercise capacity $\left(\mathrm{VO}_{2 \max }\right)$. Throughout a subsequent 120 minutes exercise on an ergometer at $50 \%$ of individual $\mathrm{VO}_{2 \max }$ free fatty acids (FFA), glucose, GH, cortisol, catecholamines and insulin were measured. Additionally substrate oxidation assessed by indirect calorimetry was determined at begin and end of exercise.

\section{Results}

Exercise capacity was lower in GHD compared to $\mathrm{CI}\left(\mathrm{VO}_{2 \max } 35.5 \pm 7.4\right.$ vs $41.5 \pm 5.5 \mathrm{ml} / \mathrm{min} * \mathrm{~kg}$, $\mathrm{p}=0.05)$. GH area under the curve (AUC-GH), peak-GH and peak-FFA were lower in GHD patients

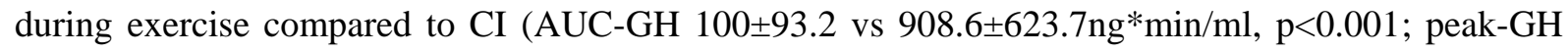
$1.5 \pm 1.53$ vs $12.57 \pm 9.36 \mathrm{ng} / \mathrm{ml}, \mathrm{p}<0.001$, peak-FFA $1.01 \pm 0.43$ vs $1.51 \pm 0.56 \mathrm{mmol} / \mathrm{l}, \mathrm{p}=0.036$, respectively). There were no significant differences for insulin, cortisol, catecholamines and glucose. Fat oxidation at the end of exercise was higher in CI compared to GHD patients $(295.7 \pm 73.9$ vs $187.82 \pm 103.8 \mathrm{kcal} / \mathrm{h}, \mathrm{p}=0.025)$.

\section{Conclusion}

A reduced availability of FFA during a 2-hours aerobic exercise and a reduced fat oxidation at the end of exercise may contribute to the decreased exercise capacity in GHD patients. Catecholamines and cortisol do not compensate for the lack of the lipolytic action of GH in patients with GHD. 


\section{Keywords}

- Growth hormone deficiency

- Exercise

- Endurance capacity

- Fuel metabolism

- Lipolysis

\section{Abbreviations}

ACTH adrenocorticotropic hormone

AUC area under the curve

BMI body mass index

CI control individuals

$\mathrm{CV} \quad$ coefficient of variation

FFA free fatty acids

GH growth hormone

GHD growth hormone deficiency

GHRH growth hormone releasing hormone

RER respiratory exchange ratio

$\mathrm{VCO}_{2} \quad$ carbon dioxide output

VO2 oxygen uptake

VO2max maximum oxygen uptake capacity 


\section{INTRODUCTION}

Hypopituitary patients with growth hormone deficiency (GHD) tend to have a reduced aerobic exercise capacity compared with sedentary control subjects $[7,18]$.

It is established that the lack of growth hormone $(\mathrm{GH})$ is accompanied by a decreased lean body mass $[6,14,27]$ and reduced performance of the cardiovascular system [7, 8]. Moreover GHD impairs the oxygen transport capacity [3]. All these factors may contribute to a reduced exercise capacity.

In healthy subjects exercise induces a strong GH secretion [17]. In patients suffering from GHD such an exercise induced GH-response is lacking $[31,32]$. Since GH is known to have a strong lipolytic effect [23] we speculate that lipolysis may also be reduced during exercise in patients with GHD compared to healthy individuals. This effect could either be compensated by an increased secretion of alternative lipolytic hormones or by changes in fuel metabolism towards an increased oxidation of carbohydrates. We, therefore, aimed at investigating the hormonal and metabolic response during exercise in GHD patients compared to matched control subject. We hypothesized that a decreased availability of free fatty acids (FFA) and possibly a reduced fat oxidation during exercise may contribute to the reduced exercise capacity in patients with GHD. 


\section{MATERIAL \& METHODS}

This was a prospective single-center open case-control study performed at the University Hospital of Bern, Switzerland. All investigations were carried out at the Division of Endocrinology, Diabetes and Clinical Nutrition. The study was approved by the local review board (Kantonale Ethikkommission, Bern) and all subjects gave written informed consent. The study was performed according to the declaration of Helsinki, the guidelines of good clinical practice, and the Swiss health laws on clinical research (Clinical.Trials.gov: NCT00491582).

\section{$\underline{\text { Participants }}$}

The study population encompassed 10 patients with severe GHD and 10 sedentary control individuals (CI) matched for gender, age, body mass index (BMI) and waist circumference. Severe GHD was defined according to the current guidelines either based on an increase of GH to $<5.1 \mathrm{ng} / \mathrm{ml}$ during an insulin tolerance test (ITT) with a nadir plasma glucose of $<2.2 \mathrm{mmol} / \mathrm{l}$ and hypoglycemic symptoms, a pathological GH releasing hormone (GHRH)/arginine test with body mass index (BMI)-dependent cut offs $\left(11.5,8.0\right.$ and $4.2 \mathrm{ng} / \mathrm{ml}$ for BMI $<25,25-30$ and $>30 \mathrm{~kg} / \mathrm{m}^{2}$ respectively), or insufficiency of at least three pituitary axes in addition to a low value for insulin-like growth factor 1 (IGF-1) [5, 21, 22]. Owing to a potential interference of oral estrogens with IGF-1 levels the diagnosis of GHD in female patients was based on stimulation testing, exclusively.

Patients were included provided they had been under stable conventional hormone replacement therapy (glucocorticoids, thyroxin and sex hormones) as needed for at least 6 months and capable to exercise on a treadmill for 2 hours. Exclusion criteria were (former or present) ACTH- or GHsecreting pituitary adenoma, abnormal liver or renal function, active neoplasia, severe cardiovascular disease (unstable coronary artery disease, heart failure New York Heart Association III-IV), diabetes mellitus, hemophilia, therapy with drugs known to affect lipid or glucose metabolism or inability to exercise. 
Participants attended the endocrine investigation unit after having fasted for at least 4 hours. All volunteers had restrained from physical activity for 72 hours before the test. Body weight was measured on an electronic balance with subjects wearing light clothes and no shoes. Height was assessed by a stadiometer. BMI was calculated as the weight divided by the square of the height. Endexpiratory waist circumference was measured with a flexible tape placed on a horizontal plane at the level of the iliac crest. Lean body mass was assessed by MRI as previously described [1]. Maximal aerobic exercise capacity was determined during an incremental workload test on a treadmill (CARDIOVIT AT-104 PC Ergo-Spirometrie, Schiller, Baar, Switzerland) until exhaustion. Increase of workload was chosen according to the estimated fitness status in order to obtain an exercise time of about $9-12$ minutes. During the test expired oxygen, carbon dioxide content and minute ventilation were measured continuously (Oxycon alpha, Jaeger, Würzburg, Germany). Furthermore, blood pressure was measured every two minutes and subjective level of exhaustion was assessed with the Borg scale. Fifty $\%$ of the heart rate at maximal aerobic exercise was calculated and the corresponding workload was chosen. After the maximal exercise test and a short break, the subjects were jogging for 30-60 minutes on the treadmill. This exercise aimed at determining the velocity and gradient of the treadmill at which the subject exhibited a heart rate that corresponded to $50 \%$ of the heart rate at maximal oxygen consumption $\left(\mathrm{VO}_{2 \max }\right)$.

\section{$\underline{\text { Two hour physical exercise on a treadmill at } 50 \% \text { of } \mathrm{VO}_{2 \max }}$}

GHD patients and CI attended the hospital after an overnight fast. Upon arrival, they received a standardized light meal. Hydrocortisone replacement therapy was administered as needed. Patients and $\mathrm{CI}$ exercised on a treadmill for $2 \mathrm{~h}$ at an intensity of $50 \%$ of $\mathrm{VO}_{2 \max }$. Glucose, free fatty acid, insulin, cortisol, GH, norepinephrine and epinephrine values were assessed immediately before start of the exercise and then every 30min. Furthermore, spirometric parameters $\left(\mathrm{VO}_{2}, \mathrm{VCO}_{2}\right.$ and RER) were measured during the first and last 15minutes of exercise (Oxycon alpha, Jaeger, Würzburg, Germany). Fat and carbohydrate oxidation were calculated based on Consolazio et al. [4].

\section{$\underline{\text { Biochemical analysis }}$}


Blood glucose levels were measured by a glucose-oxidase method using YSI2300 (Yellow Springs Instruments, Yellow Springs, OH, USA). Insulin concentrations were measured with electrochemiluminescence immunoassays (Roche Modular-E170; Roche Diagnostics, Rotkreuz, Switzerland) The intra-assay CV was $1.1 \%$ and the inter-assay CV was 3.6\%. Cortisol concentrations were measured with electro-chemiluminescence immunoassays (Roche Modular-E170; Roche Diagnostics, Rotkreuz, Switzerland). The intra-assay CV was $1.7 \%$ and the inter-assay CV was $2.2 \%$. FFA concentrations were determined using a commercially available kit (Wako Pure Chemical, VWR International, Dietikon, Switzerland). The intra-assay CV was $1.5 \%$ and the inter-assay CV was $15 \%$. Serum GH concentrations were determined with an enzymatically amplified, two-step sandwich immunoassay (Diagnostic System Laboratories, Webster, TX, USA; The interassay CV was 6.5\% and the intraassay CV 4.3\%). Plasma catecholamines (norepinephrine and epinephrine) were analyzed using HPLC with amperometric detection (modified method of the RECIPE kit (ClinRep®, RECIPE Chemicals and Instruments GmbH, Munich, Germany) [13].

\section{$\underline{\text { Statistical analysis }}$}

Results are expressed as mean \pm standard deviation (SD), unless otherwise specified. The area under the curve (AUC) was calculated using cubic splines. Incremental AUC was determined using the delta values between the nadir and remaining measurements of every individual. Continuous variables were analyzed for normal distribution using Shapiro-Wilk test and qq-plots. Parametric variables were compared using ttests and repeated measure analysis of variance. Non-parametric variables were analyzed using Wilcoxon rank sum and Wilcoxon signed rank tests or Friedman tests. Within group comparison was performed by paired tests, whereas between group analysis was performed by unpaired tests. In case of multiple comparison postestimation procedure applying a Bonferroni or Dunn's correction was used. A p-value of $<0.05$ was considered statistically significant. All statistical analyses were performed with Stata version 12.1 (Stata Corp., College Station, TX) and GraphPad Prism version 6.0 (GraphPad Software, La Jolla, California, USA). 


\section{RESULTS}

\section{$\underline{\text { Participants' characteristics }}$}

Ten GHD patients (6 male / 4 female) and ten sedentary CI matched for gender, age, BMI and waist circumference were included into the study. Among the ten GHD individuals substitution of corticotropic, gonadotropic and thyreotropic axis was necessary in five, eight and five patients, respectively. GHD patients had significantly lower IGF-1 levels compared to CI $(66.6 \pm 22.9 \mathrm{ng} / \mathrm{ml} \mathrm{vs}$ $117.1 \pm 30.5 \mathrm{ng} / \mathrm{ml}, \mathrm{p}<0.001)$ and had a reduced exercise capacity compared to $\mathrm{CI}$ assessed by $\mathrm{VO}_{2 \max }$ $(35.5 \pm 7.4 \mathrm{ml} / \mathrm{min} * \mathrm{~kg}$ vs $41.5 \pm 5.5 \mathrm{ml} / \mathrm{min} * \mathrm{~kg}, \mathrm{p}=0.05)$. Additional clinical characteristics are summarized in Table 1.

\section{$\underline{\text { Metabolites }}$}

Metabolic response during exercise is summarized in Table 2. In patients with GHD Glucose concentrations were stable throughout the exercise (ANOVA $\mathrm{p}=0.52$ ), whereas FFA showed a significant increase during exercise with peak level at $120 \mathrm{~min}(\mathrm{p}<0.001$; see figure $1 \mathrm{a} \mathrm{\&} 1 \mathrm{~b})$. In CI Glucose concentrations were stable throughout the exercise (ANOVA $p=0.32$ ) but FFA concentrations showed a more pronounced increase during exercise (ANOVA $\mathrm{p}<0.001$; see figure 1a $\underline{\text { \& }}$ b) compared to GHD, resulting in a significantly higher FFA-peak value $(\mathrm{p}=0.036)$ and a trend towards higher AUCs for FAA in CI compared to GHD ( $\mathrm{p}$ for AUC $=0.27$, incremental AUC-FFA $54.8 \pm 26.9$ vs $35 \pm 25.5 \mathrm{mmol} * \mathrm{~min} / \mathrm{l}$ for $\mathrm{CI}$ and GHD, respectively; $\mathrm{p}=0.07$ ).

\section{$\underline{\text { Hormones }}$}

Hormonal response to the 120 minute exercise are summarized in Table 2. In GHD GH values showed a slight but significant increase after 30 minutes $(1.46 \pm 1.55 \mathrm{ng} / \mathrm{ml})$ and 60 minutes $(0.78 \pm 0.71$ $\mathrm{ng} / \mathrm{ml}$ ) of exercise (p compared to baseline $<0.001$ and $<0.05$ at 30 and 60 minutes, respectively; see figure 2a). As depicted in figure $2 \mathrm{~b}$ cortisol values tended to drop slightly in GHD patients after 30min 
and remained stable for the rest of the exercise (ANOVA $\mathrm{p}=0.72$ ). Furthermore epinephrine and NE showed a significant increase during exercise in patients suffering from GHD (Friedman test p-value for Adrenalin $=0.015$ and for NA $<0.001$, respectively; see figure $2 \mathrm{c} \& 2 \mathrm{~d}$ ). Insulin level significantly decreased during exercise in GHD patients (Friedman Test $\mathrm{p}<0.001$ ).

In $\mathrm{CI}$ there was a significant and transient increase of $\mathrm{GH}$ with highest values after 30min (GH $11.55 \pm$ $10.16 \mathrm{ng} / \mathrm{ml}$, p compared to baseline $<0.01$ ) and a continuous decline during the following 90 minutes of exercise (figure 2a). In CI cortisol values tended to slightly drop after 30 minutes and then raised again during the rest of exercise ANOVA $p=0.13$; see figure $2 b$ ). Epinephrine and NE showed a significant increase in CI throughout the entire exercise $(\mathrm{p}<0.001$ for Epinephrine and NE) with highest values at 120 minutes of exercise (see figure $2 \mathrm{c} \& 2 \mathrm{~d}$ ).

AUC and peak values of GH were significantly lower in GHD patients during exercise compared to CI $(\mathrm{p}<0.001$ for AUC- and peak-GH). AUC-cortisol and peak-cortisol were similar in GHD and CI ( $\mathrm{p}$ for AUC-cortisol $=0.44, \mathrm{p}$ for peak-cortisol $=0.40$ ). When comparing the incremental AUCs of cortisol there was a trend towards higher cortisol values in CI compared to GHD (incremental AUCcortisol $11^{\prime} 199 \pm 8214$ vs. $\left.8^{\prime} 507 \pm 10^{\prime} 045 \mathrm{mmol}^{*} \mathrm{~min} / \mathrm{l}, \mathrm{p}=0.059\right)$. AUC and peak concentrations of catecholamines and insulin did not significantly differ between GHD patients and CI.

\section{$\underline{\text { Substrate oxidation }}$}

Oxygen uptake, Carbon dioxid output, respiratory quotient, as well as fat and carbohydrate oxidation were similar in GHD patients and CI at begin of exercise (Table 3). At the end of the 120minutes exercise period CI showed a significant increase of $\mathrm{VO}_{2}(\mathrm{p}=0.047)$ and Fat oxidation $(\mathrm{p}=0.028)$ compared to the start of exercise. In GHD patients substrate oxidation parameters were similar between start and end of exercise resulting in a significantly higher RER ( $\mathrm{p}=0.04)$ and a significantly lower fat oxidation rate $(\mathrm{p}=0.025)$ in GHD compared to CI. 


\section{DISCUSSION}

To our knowledge this is the first study examining fuel metabolism and counterregulatory hormones in patients with GHD and CI. The main findings can be summarized as follows: First, there was a reduced exercise capacity in GHD patients compared to CI. Second, during a standardized aerobic exercise of 120 minutes duration FFA levels increased in both groups but peak FFA values were significantly lower in GHD patients compared to CI, whereas glucose availability was similar in GHD compared to CI. Third, patients with GHD had a higher RER and a lower fat oxidation compared to CI at the end of the 120 minutes exercise. Fourth, lipolytic hormones such as catecholamines, and cortisol do not completely compensate for the lack of lipolytic action of GH in patients with GHD during exercise.

A reduced exercise capacity based on $\mathrm{VO}_{2 \max }$ measurement in patients with GHD is consistent with previous studies $[7,29]$. Besides a possible metabolic factor there are several possible factors that may contribute to this finding: GHD is characterized by a reduced lean body mass $[6,14]$, impaired cardiac function, namely alterations in preload and afterload $[2,18]$, an elevated peripheral vascular resistance [28], pointing towards a negative effect of GHD on the performance of the cardiovascular system. This hypothesis is further supported by the presence of GH and IGF-1 receptors in myocardium and blood vessels $[10,16]$, which makes a direct effect of GH and IGF-1 on the heart muscle and cardiac and cardiovascular function likely. Additionally, GHD impairs the oxygen transport capacity, mainly by a reduced erythropoiesis [3].

It is established that in healthy individuals physical exercise results in an increase in GH secretion which, in turn, induces lipolysis, as evidenced by an increase in FFA concentrations, as documented in the present study and in previous work [20, 23]. However, in patients with GHD Kanaley et al. have shown that administration of GH during exercise leads to a marked increase in FFA as well as FFA fluxes [19], in keeping with our findings and further supporting the importance of the lipolytic action of GH during exercise. In contrast, GH withdrawal decreases fat turnover during exercise, which may contribute to a reduced exercise capacity in GHD [12]. The lower systemic availability of FFA in GHD patients suggests a reduced lipolytic activity in GHD compared to CI. These findings may be 
explained by a reduced lipase activity in adipose tissue of GHD patients during exercise. Previous studies in exercising healthy individuals showed an increased activity of triacylglycerol lipase activity [25]. Since adipose tissue biopsy was not part of the present study we can only speculate on GH mediated differences in triacylglycerol lipase activity.

Of interest, the differences in serum FFA concentrations between GHD and CI were most pronounced at the end of the 2-h exercise period suggesting that the other lipolytic hormones such as catecholamines and cortisol were sufficient to increase FFA availability at the beginning of the 2-h exercise. Interestingly, these findings were paralleled by a significantly higher fat oxidation in CI compared to GHD patients at the end of exercise, indicating that there is not only an impaired availability of FFA during exercise in GHD patients but the lack of GH may also negatively impact on FFA uptake and intracellular trafficking of FFA towards the mitochondria including oxidation as suggested by previous work [29]. Based on these results it is possible that - besides the well-known factors such as reduced lean body mass, oxygen transport capacity and negative effect of GHD on the performance of the cardiovascular system - metabolic factors, in particular FFA availability, uptake and oxidation may contribute to the reduced exercise capacity seen in patients with GHD [12]. Furthermore high-dose GH increases lipolysis and FFA availability at rest, during and after exercise [15]. In addition, GH replacement over 3-12 months was shown to improve aerobic exercise capacity and muscle mass [26].

An increase in catecholamines, cortisol and $\mathrm{GH}$, as well as reduction in insulin-secretion are well known hormonal responses to exercise in healthy individuals $[9,30]$ and were also observed in the present study. Besides the reduced GH secretion and a flattened cortisol response we found similar hormonal secretion patterns during the exercise also for the GHD patients. The flattened cortisol profile can be explained by the fact that five of the ten GHD patients additionally suffered from hypothalamo-pituitary-adrenal axis insufficiency and were, therefore, substituted with hydrocortisone as appropriate before the exercise. We cannot exclude a certain influence of the flattened cortisol profile on lipolysis and fat-utilization in the GHD group, since cortisol increases on one hand lipolysis [11] and on the other hand intravascular triglyceride degradation by activating lipoprotein lipase [24]. 
Nevertheless AUC and peak-values of cortisol in GHD and CI during exercise were not statistically different, which makes a major influence of the substituted cortisol deficiency unlikely. Of interest, the blunted GH response in GHD patients during exercise was neither compensated by an increased catecholamine- nor by a reduced insulin-secretion compared to CI.

The strength of this study lies in the careful matching of GHD patients and CI including age, gender, BMI and waist circumference. Nevertheless we have to acknowledge several limitations: 1) We were only able to measure FFA and Glucose concentrations during exercise. Stable isotope studies would be necessary to assess the flux of FFA and Glucose in order to further substantiate the conclusion of the study. 2) The study was not designed to separately assess the impact and extent of the potential different factors in GHD that contribute to the impaired exercise capacity. 3) Although GHD patients and CI were carefully matched the cross-sectional study design is accompanied by several factors possibly influencing fat utilization (as for instance differences in physical fitness and pituitary hormone replacement therapy).

In conclusion the findings of this study suggest that reduced FFA availability, uptake and oxidation may contribute to the observed reduced exercise capacity in GHD patients. Other lipolytic hormones such as catecholamines do not compensate the metabolic role of GH during exercise in GHD patients. 


\section{$\underline{\text { Acknowledgments }}$}

We thank all the enthusiastic patients and control subjects who agreed to participate in this study. 


\section{REFERENCES}

[1] T. Buehler, N. Ramseier, J. Machann, N.F. Schwenzer, C. Boesch, Magnetic resonance imaging based determination of body compartments with the versatile, interactive sparse sampling (VISS) method, Journal of magnetic resonance imaging : JMRI, 36 (2012) 951-960.

[2] P.V. Carroll, E.R. Christ, B.A. Bengtsson, L. Carlsson, J.S. Christiansen, D. Clemmons, R. Hintz, K. Ho, Z. Laron, P. Sizonenko, P.H. Sonksen, T. Tanaka, M. Thorne, Growth hormone deficiency in adulthood and the effects of growth hormone replacement: a review. Growth Hormone Research Society Scientific Committee, The Journal of clinical endocrinology and metabolism, 83 (1998) 382-395. [3] E.R. Christ, M.H. Cummings, N.B. Westwood, B.M. Sawyer, T.C. Pearson, P.H. Sonksen, D.L. Russell-Jones, The importance of growth hormone in the regulation of erythropoiesis, red cell mass, and plasma volume in adults with growth hormone deficiency, The Journal of clinical endocrinology and metabolism, 82 (1997) 2985-2990.

[4] C.F.J. Consolazio, Robert E \& Pecora, Louis Joseph, Physiological measurements of metabolic functions in man, Blakiston Division, McGraw-Hill, New York, 1963.

[5] G. Corneli, C. Di Somma, R. Baldelli, S. Rovere, V. Gasco, C.G. Croce, S. Grottoli, M. Maccario, A. Colao, G. Lombardi, E. Ghigo, F. Camanni, G. Aimaretti, The cut-off limits of the GH response to GHreleasing hormone-arginine test related to body mass index, European journal of endocrinology / European Federation of Endocrine Societies, 153 (2005) 257-264.

[6] R.C. Cuneo, F. Salomon, C.M. Wiles, R. Hesp, P.H. Sonksen, Growth hormone treatment in growth hormone-deficient adults. I. Effects on muscle mass and strength, Journal of applied physiology (Bethesda, Md. : 1985), 70 (1991) 688-694.

[7] R.C. Cuneo, F. Salomon, C.M. Wiles, R. Hesp, P.H. Sonksen, Growth hormone treatment in growth hormone-deficient adults. II. Effects on exercise performance, Journal of applied physiology (Bethesda, Md. : 1985), 70 (1991) 695-700.

[8] R.C. Cuneo, F. Salomon, P. Wilmshurst, C. Byrne, C.M. Wiles, R. Hesp, P.H. Sonksen, Cardiovascular effects of growth hormone treatment in growth-hormone-deficient adults: stimulation of the renin-aldosterone system, Clinical science (London, England : 1979), 81 (1991) 587592.

[9] S.N. Davis, P. Galassetti, D.H. Wasserman, D. Tate, Effects of gender on neuroendocrine and metabolic counterregulatory responses to exercise in normal man, The Journal of clinical endocrinology and metabolism, 85 (2000) 224-230.

[10] P. Delafontaine, K.E. Bernstein, R.W. Alexander, Insulin-like growth factor I gene expression in vascular cells, Hypertension, 17 (1991) 693-699.

[11] C.B. Djurhuus, C.H. Gravholt, S. Nielsen, A. Mengel, J.S. Christiansen, O.E. Schmitz, N. Moller, Effects of cortisol on lipolysis and regional interstitial glycerol levels in humans, American journal of physiology. Endocrinology and metabolism, 283 (2002) E172-177.

[12] J. Gibney, M.L. Healy, M. Stolinski, S.B. Bowes, C. Pentecost, L. Breen, C. McMillan, D.L. RussellJones, P.H. Sonksen, A.M. Umpleby, Effect of growth hormone (GH) on glycerol and free fatty acid metabolism during exhaustive exercise in $\mathrm{GH}$-deficient adults, The Journal of clinical endocrinology and metabolism, 88 (2003) 1792-1797.

[13] E. Grouzmann, M. Fathi, M. Gillet, A. de Torrente, C. Cavadas, H. Brunner, T. Buclin, Disappearance rate of catecholamines, total metanephrines, and neuropeptide $\mathrm{Y}$ from the plasma of patients after resection of pheochromocytoma, Clinical chemistry, 47 (2001) 1075-1082.

[14] A. Hazem, M.B. Elamin, I. Bancos, G. Malaga, G. Prutsky, J.P. Domecq, T.A. Elraiyah, N.O. Abu Elnour, Y. Prevost, J.P. Almandoz, C. Zeballos-Palacios, E.R. Velasquez, P.J. Erwin, N. Natt, V.M. Montori, M.H. Murad, Body composition and quality of life in adults treated with GH therapy: a systematic review and meta-analysis, European journal of endocrinology / European Federation of Endocrine Societies, 166 (2012) 13-20.

[15] M.L. Healy, J. Gibney, C. Pentecost, P. Croos, D.L. Russell-Jones, P.H. Sonksen, A.M. Umpleby, Effects of high-dose growth hormone on glucose and glycerol metabolism at rest and during exercise 
in endurance-trained athletes, The Journal of clinical endocrinology and metabolism, 91 (2006) 320327.

[16] J. Isgaard, H. Wahlander, M.A. Adams, P. Friberg, Increased expression of growth hormone receptor mRNA and insulin-like growth factor-I mRNA in volume-overloaded hearts, Hypertension, 23 (1994) 884-888.

[17] P.J. Jenkins, Growth hormone and exercise, Clinical endocrinology, 50 (1999) 683-689.

[18] J.O. Jorgensen, S.A. Pedersen, L. Thuesen, J. Jorgensen, T. Ingemann-Hansen, N.E. Skakkebaek, J.S. Christiansen, Beneficial effects of growth hormone treatment in GH-deficient adults, Lancet (London, England), 1 (1989) 1221-1225.

[19] J.A. Kanaley, R. Dall, N. Moller, S.C. Nielsen, J.S. Christiansen, M.D. Jensen, J.O. Jorgensen, Acute exposure to $\mathrm{GH}$ during exercise stimulates the turnover of free fatty acids in $\mathrm{GH}$-deficient men, Journal of applied physiology (Bethesda, Md. : 1985), 96 (2004) 747-753.

[20] J.A. Kanaley, J.Y. Weltman, K.S. Pieper, A. Weltman, M.L. Hartman, Cortisol and growth hormone responses to exercise at different times of day, The Journal of clinical endocrinology and metabolism, 86 (2001) 2881-2889.

[21] M.E. Molitch, D.R. Clemmons, S. Malozowski, G.R. Merriam, S.M. Shalet, M.L. Vance, P.A. Stephens, Evaluation and treatment of adult growth hormone deficiency: an Endocrine Society Clinical Practice Guideline, The Journal of clinical endocrinology and metabolism, 91 (2006) 16211634.

[22] M.E. Molitch, D.R. Clemmons, S. Malozowski, G.R. Merriam, M.L. Vance, Evaluation and treatment of adult growth hormone deficiency: an Endocrine Society clinical practice guideline, The Journal of clinical endocrinology and metabolism, 96 (2011) 1587-1609.

[23] N. Moller, J.O. Jorgensen, O. Schmitz, J. Moller, J. Christiansen, K.G. Alberti, H. Orskov, Effects of a growth hormone pulse on total and forearm substrate fluxes in humans, The American journal of physiology, 258 (1990) E86-91.

[24] M. Ottosson, K. Vikman-Adolfsson, S. Enerback, G. Olivecrona, P. Bjorntorp, The effects of cortisol on the regulation of lipoprotein lipase activity in human adipose tissue, The Journal of clinical endocrinology and metabolism, 79 (1994) 820-825.

[25] A. Petridou, V. Mougios, Acute changes in triacylglycerol lipase activity of human adipose tissue during exercise, Journal of lipid research, 43 (2002) 1331-1334.

[26] K.Z. Rubeck, S. Bertelsen, P. Vestergaard, J.O. Jorgensen, Impact of GH substitution on exercise capacity and muscle strength in GH-deficient adults: a meta-analysis of blinded, placebo-controlled trials, Clinical endocrinology, 71 (2009) 860-866.

[27] F. Salomon, R.C. Cuneo, R. Hesp, P.H. Sonksen, The effects of treatment with recombinant human growth hormone on body composition and metabolism in adults with growth hormone deficiency, The New England journal of medicine, 321 (1989) 1797-1803.

[28] E.M. Scott, J.P. Greenwood, J.B. Stoker, D.A. Mary, S.G. Gilbey, Sympathetic nerve hyperactivity is associated with increased peripheral vascular resistance in hypopituitary patients with growth hormone deficiency, Clinical endocrinology, 56 (2002) 759-763.

[29] R. Trepp, M. Fluck, C. Stettler, C. Boesch, M. Ith, R. Kreis, H. Hoppeler, H. Howald, J.P. Schmid, P. Diem, E.R. Christ, Effect of GH on human skeletal muscle lipid metabolism in GH deficiency, American journal of physiology. Endocrinology and metabolism, 294 (2008) E1127-1134.

[30] W.W. Winder, R.C. Hickson, J.M. Hagberg, A.A. Ehsani, J.A. McLane, Training-induced changes in hormonal and metabolic responses to submaximal exercise, Journal of applied physiology:

respiratory, environmental and exercise physiology, 46 (1979) 766-771.

[31] T. Zueger, S. Alleman, E.R. Christ, C. Stettler, Exercise-induced GH secretion in the assessment of GH deficiency in adult individuals, European journal of endocrinology / European Federation of Endocrine Societies, 165 (2011) 723-728.

[32] T. Zueger, J. Bucher, E.R. Christ, C. Stettler, Peak oxygen uptake test in the assessment of growth hormone deficiency, Applied physiology, nutrition, and metabolism = Physiologie appliquee, nutrition et metabolisme, 39 (2014) 852-855. 


\section{TABLES}

Table 1. Clinical characteristics of GHD patients and control individuals

\begin{tabular}{|c|c|c|c|}
\hline & GHD & CI & p-values \\
\hline Male/female & $6 / 4$ & $6 / 4$ & \\
\hline Age (years) & $42.5( \pm 12.7)$ & $42.9( \pm 12.7)$ & 0.95 \\
\hline BMI $\left(\mathrm{kg} / \mathrm{m}^{2}\right)$ & $26.6( \pm 3.8)$ & $25.3( \pm 5.3)$ & 0.53 \\
\hline LBM (kg) & $50.3( \pm 11.3)$ & $50.9( \pm 12.7)$ & 0.92 \\
\hline Waist (cm) & $89.3( \pm 12.9)$ & $90.7( \pm 19.1)$ & 0.85 \\
\hline $\mathrm{VO}_{2 \max }(\mathrm{ml} / \mathrm{min} * \mathrm{~kg})$ & $35.5( \pm 7.4)$ & $41.5( \pm 5.5)$ & 0.05 \\
\hline Watt $_{\max }(\mathbf{W})$ & $251.0( \pm 60.1)$ & $286.4( \pm 89.6)$ & 0.32 \\
\hline IGF-1 (ng/ml) & $66.6( \pm 22.9)$ & $117.1( \pm 30.5)$ & $<0.001$ \\
\hline
\end{tabular}

$\mathrm{GHD}=$ growth hormone deficient patients; $\mathrm{CI}=$ control individuals; $\mathrm{LBM}=$ lean body mass; Waist $=$ waist circumference; $\mathrm{VO}_{2 \max }=$ maximal oxygen uptake. $\mathrm{Watt}_{\max }=$ maximal achieved watts on ergometer during incremental exercise test. Results are mean \pm SD. Bold p-values, statistically significant. 
Table 2. Hormonal and metabolic response in GHD patients and control individuals during exercise

\begin{tabular}{|c|c|c|c|c|c|c|}
\hline & \multicolumn{3}{|c|}{ peak values } & \multicolumn{3}{|c|}{ AUC } \\
\hline & GHD & CI & p-values & GHD & CI & p-values \\
\hline Glucose (mmol/l) & $4.63 \pm 0.28$ & $4.70 \pm 0.49$ & 0.72 & $503.1 \pm 66.8$ & $529.3 \pm 55.2$ & 0.60 \\
\hline FFA $(\mathbf{m m o l} / \mathbf{l})$ & $1.01 \pm 0.43$ & $1.51 \pm 0.56$ & 0.036 & $82.9 \pm 41.4$ & $103.0 \pm 35.9$ & 0.268 \\
\hline GH (ng/ml) & $1.50 \pm 1.53$ & $12.57 \pm 9.36$ & $<0.001$ & $100.0 \pm 93.2$ & $908.6 \pm 623.7$ & $<0.001$ \\
\hline Cortisol (nmol/l) & $373.8 \pm 174.1$ & $434.0 \pm 133.4$ & 0.40 & $31304 \pm 14581$ & $36153 \pm 12661$ & 0.44 \\
\hline Insulin (mU/l) & $11.80 \pm 16.81$ & $12.38 \pm 7.73$ & 0.13 & $538.7 \pm 707.6$ & $528.6 \pm 358.4$ & 0.36 \\
\hline NE (nmol/l) & $6.60 \pm 3.32$ & $7.83 \pm 1.85$ & 0.32 & $583.6 \pm 239.7$ & $742.6 \pm 200.2$ & 0.26 \\
\hline Epinephrin (nmol/l) & $0.91 \pm 0.74$ & $0.77 \pm 0.52$ & 0.63 & $77.1 \pm 79.5$ & $49.1 \pm 32.4$ & 0.32 \\
\hline
\end{tabular}

$\mathrm{GHD}=$ growth hormone deficient patients; $\mathrm{CI}=$ control individuals; $\mathrm{FFA}=$ free fatty acids; $\mathrm{GH}=$ growth hormone; $\mathrm{NE}=\mathrm{Norepinephrin}$. AUC $=$ area under the curve during 120min exercise. Incremental AUC $=$ Incremental area under the curve during 120min exercise. Results are mean $\pm \mathrm{SD}$. Bold p-values, statistically significant. 
Table 3. Spirometric data and substrate oxidation in GHD patients and control individuals

\begin{tabular}{|c|c|c|c|c|c|c|c|c|}
\hline & & & & & \multicolumn{4}{|c|}{ p-values } \\
\hline & \multicolumn{2}{|c|}{ start of exercise (SoE) } & \multicolumn{2}{|c|}{ end of exercise (EoE) } & \multicolumn{2}{|c|}{ GHD vs CI } & \multicolumn{2}{|c|}{ SoE vs EoE } \\
\hline & GHD & CI & GHD & CI & baseline & EoE & GHD & CI \\
\hline $\mathrm{VO}_{2}(1 / \mathrm{min})$ & $17.84 \pm 3.18$ & $17.92 \pm 3.47$ & $18.09 \pm 3.27$ & $20.97 \pm 2.74$ & 0.96 & 0.067 & 0.19 & 0.047 \\
\hline $\mathrm{VCO}_{2}(1 / \mathrm{min})$ & $15.56 \pm 3.49$ & $15.03 \pm 3.65$ & $15.56 \pm 3.53$ & $16.75 \pm 2.38$ & 0.76 & 0.42 & 0.97 & 0.20 \\
\hline RER & $0.87 \pm 0.08$ & $0.83 \pm 0.06$ & $0.86 \pm 0.07$ & $0.80 \pm 0.04$ & 0.28 & 0.040 & 0.23 & 0.19 \\
\hline FATox (kcal/h) & $175.88 \pm 117.23$ & $213.4 \pm 103.82$ & $187.82 \pm 103.84$ & $295.72 \pm 73.89$ & 0.49 & 0.025 & 0.42 & 0.028 \\
\hline CHOox (kcal/h) & $219.64 \pm 122.06$ & $189.27 \pm 104.95$ & $206.98 \pm 104.23$ & $153.63 \pm 73.39$ & 0.59 & 0.24 & 0.46 & 0.37 \\
\hline
\end{tabular}

$\mathrm{GHD}=$ growth hormone deficient patients; $\mathrm{CI}=$ control individuals; $\mathrm{VO} 2=$ oxygen consumption; $\mathrm{VCO} 2$ = carbon dioxid output; RER = respiratory quotient;

FATox $=$ fat oxidation CHOox $=$ carbohydrate oxidation. Results are mean \pm SD. Bold p-values, statistically significant 


\section{FIGURE CAPTIONS}

\section{$\underline{\text { Figure } 1}$}

Mean \pm S.E.M. concentrations of free fatty acids (panel A), glucose (panel B) and insulin (panel C) during exercise for GHD patients (black circles with solid lines) and control individuals (white squares with dashed lines). * p-value for difference between GHD and CI $<0.05$.

\section{$\underline{\text { Figure } 2}$}

Mean \pm S.E.M. concentrations of GH (panel A), cortisol (panel B), norepinephrine (panel C) and epinephrine (panel D) during exercise for GHD patients (black circles with solid lines) and control individuals (white squares with dashed lines). ${ }^{* *}$ p-value for difference between GHD and CI $<0.01$. *** p-value for difference between GHD and CI $<0.001$ 


\section{Figure 1}

A

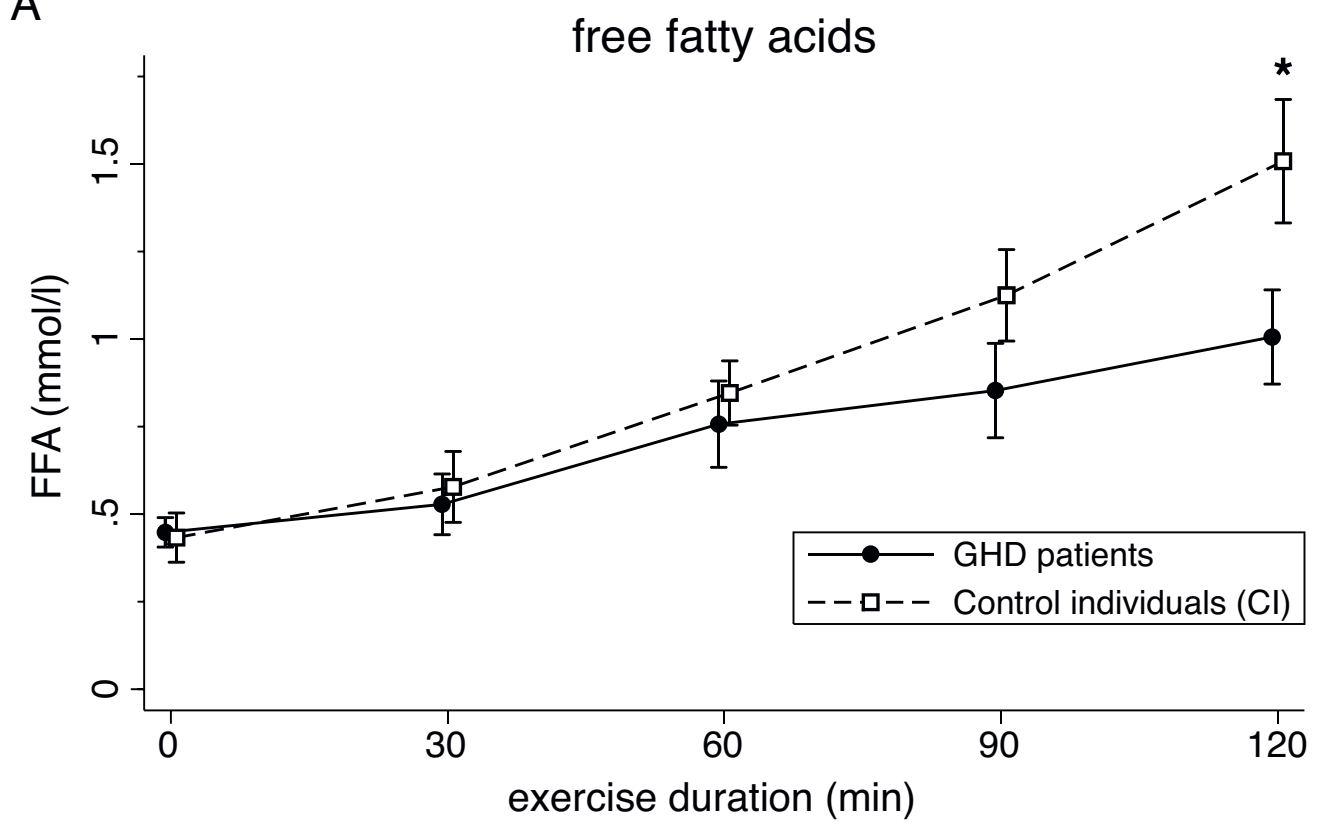

B

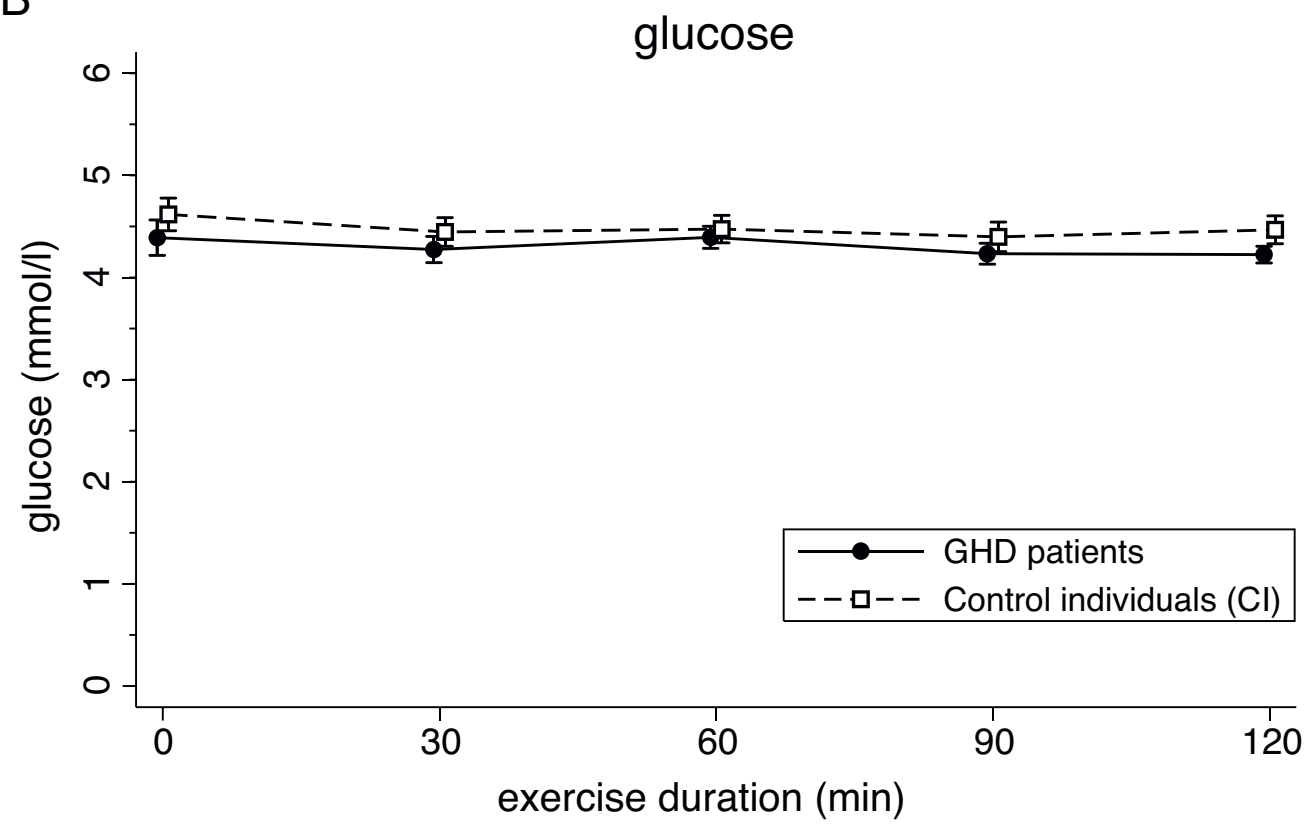

C

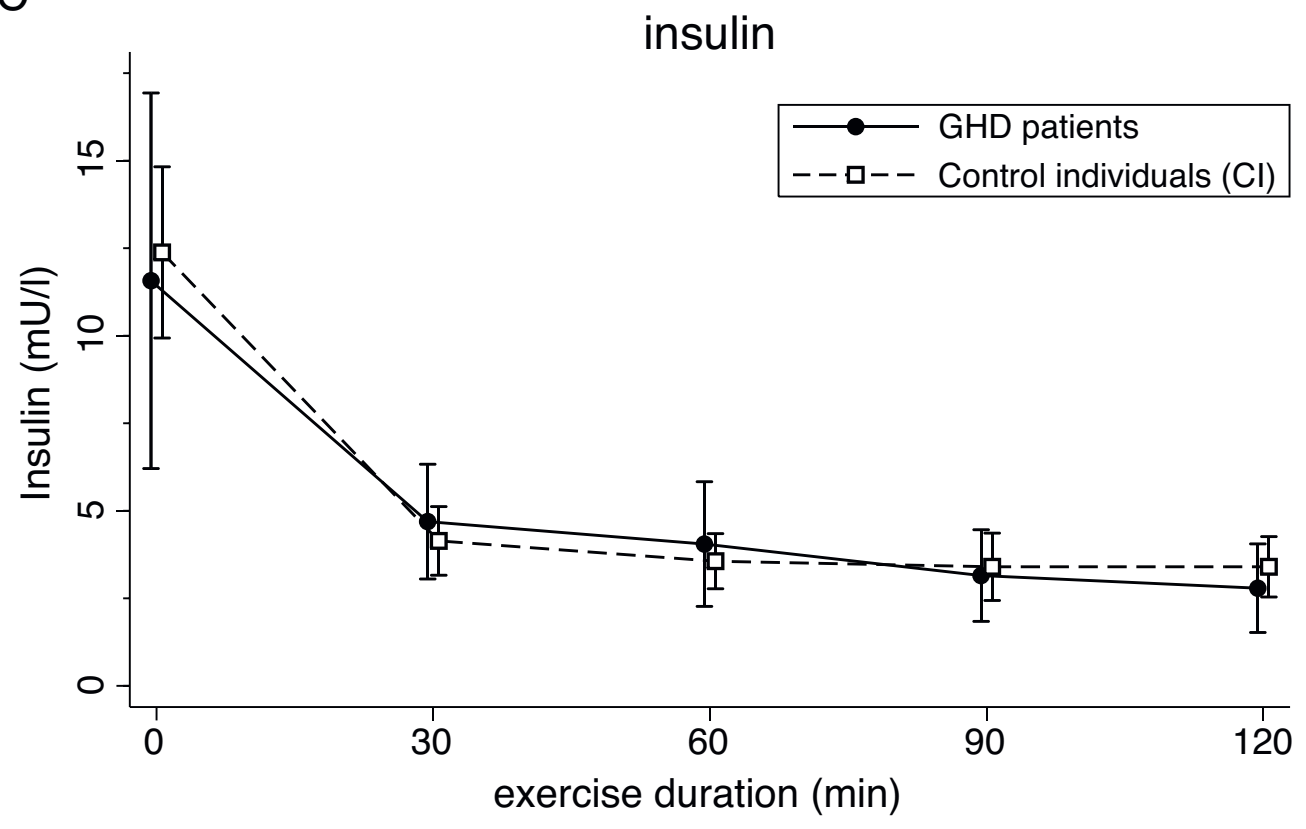


Figure 2
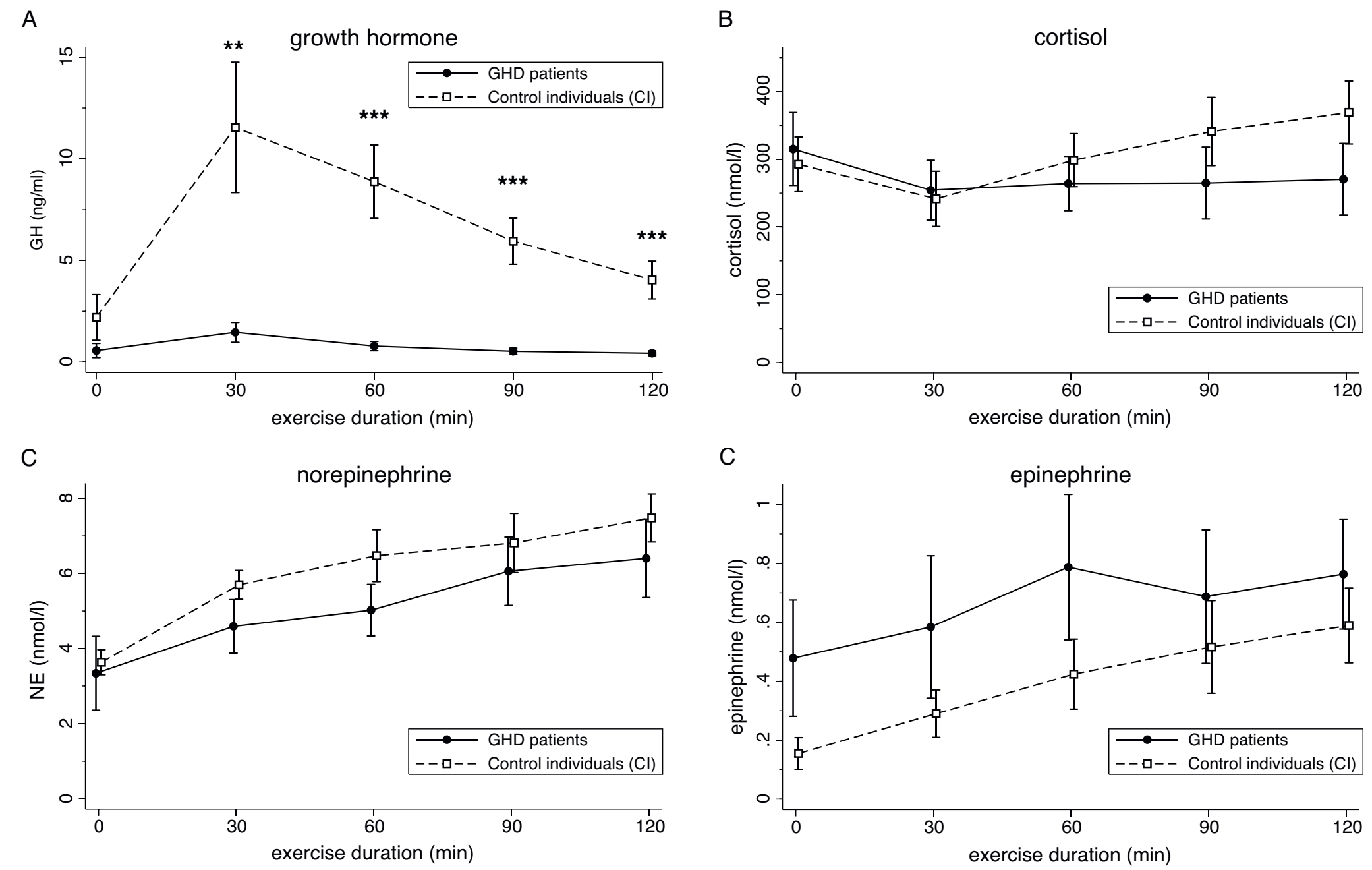